\title{
Kosutnjak: landscape as a learning system
}

\author{
A. Nikezic \& N. Jankovic \\ Faculty of Architecture, University in Belgrade, Serbia
}

\begin{abstract}
Nature can become a resource of contemporary life in the city where leisure asks for new sanctuaries over and over again. Nature does not stop only at the physical, but also affects the process of urban living, through the intersecting and intertwining of architecture and nature, making a new urban landscape. During each architectural intervention in the natural landscape, it is necessary to reconsider the position, scope, program, and its measure in the context of contemporary city life, which will be viewed from the ratio of the materiality of architecture and landscape.

This paper reports results and methods of Master students' research on the relation between nature and architecture, in the particular context of Kosutnjak, park-forest and city resort that covers an area of 330 hectares at an altitude of $250 \mathrm{~m}$, in Belgrade.

During the first year of Master studies, working two academic years at the same location, two groups of ten to fifteen students have had the task of examining the positioning of architectural intervention in the context of Kosutnjak. During the semester, they dealt with the physical and program review of the relationship of the inherited structures and landscapes through finding new positions for architecture in relation to city-nature, resulting in a change of identity of the urban landscape.

Students were expected to find new possibilities and limitations of networking nature and the architecture, through a new offer of small and hidden architectural intervention that changes nature, does not disturb its rhythm and includes all of its attributes as positive stimulants, thus creating the architecture that emphasizes and promotes nature.
\end{abstract}

Keywords: architecture, nature, urban landscape, students' work. 


\section{Introduction}

During each architectural intervention in the natural landscape, it is necessary to reconsider the position, scope, program, and its measure in the context of contemporary city life, which will inevitably be viewed from the ratio of materiality of architecture and landscape. Human behavior and actions influence the structure and function of landscape thus affecting the process of urban living, by making a new "cultural landscape" [1].

This article presents results from the research taken under the Master course of Architectural Design on the Faculty of Architecture, University in Belgrade. Through establishing relationship between landscape sustainability and people's contact with nature, we try to give some indication of changes in the architectural paradigms under the current process of sustainable development of cities (with special focus on current and acute process of climate change), as well as possible guidelines for architectural action in the landscape of contemporary city.

Before reporting results and methods of students' research we have to say a few words about Kosutnjak, natural resort in the middle of Belgrade, Serbia. Kosutnjak represents a park-forest and a city resort, a sort of habitat for diverse species of wildlife covering an area of 330 hectares at an altitude of $250 \mathrm{~m}$. It is a forest on the slopes of the town center, bordered with high density housing structures. Its importance and position in the historical, socio-political and economic sense has been changing with the city since its beginning.

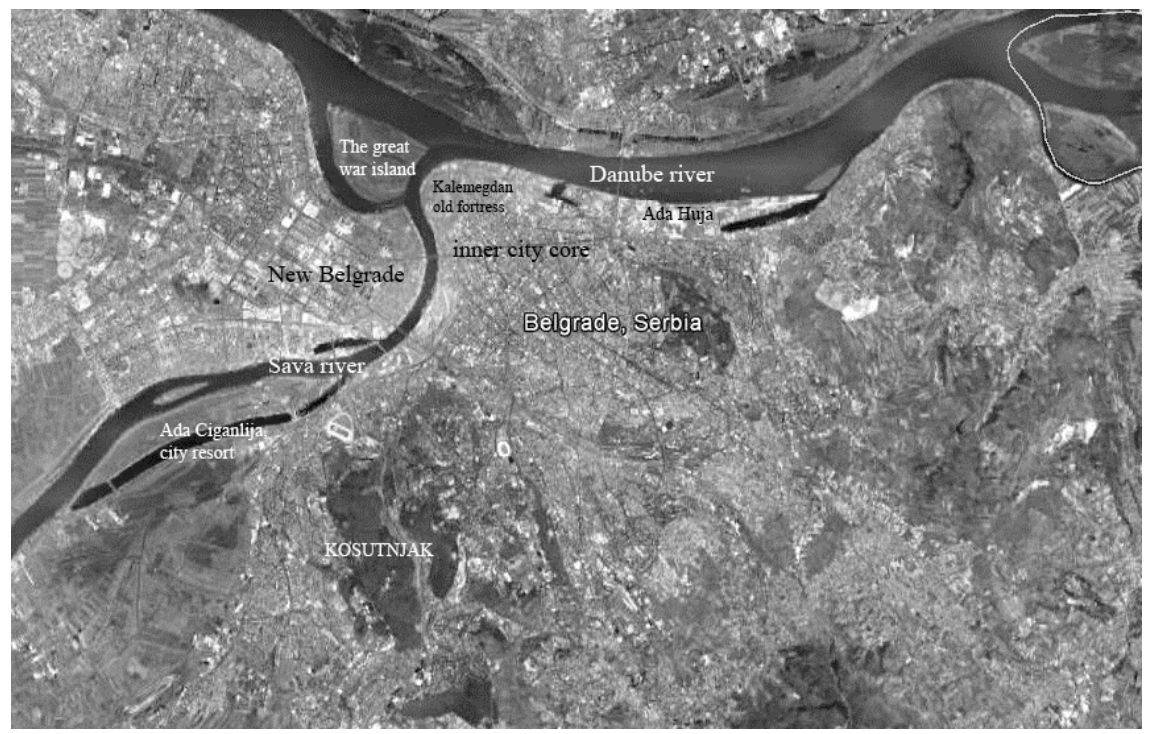

Figure 1: $\quad$ Position of Kosutnjak on the map of Belgrade.

Today Kosutnjak is everything and nothing, the space lost in the narrow passage between transition and history, between culture and landscape, between 
heritage and ruin. It has an epithet of being public, which does not imply an urban character. Unfortunately, it is not included in the mainstream of contemporary cultural city life, except in few isolated and quite small moments, such as white marathon, blues festival or forest festival, all of which are not making recognizable identity of the place. With its topological, culturalhistorical and aesthetic-visual distinctive pattern, as a holistic landscape [2], Kosutnjak could contribute to the improvement of overall environmental quality of Belgrade urban area.

Because architecture and landscape present distinct, even antithetical phenomena, architectural intervention requires acts of translation. It challenges a new perspective for cultural landscape approach as a means of its development and recognition, thus trying to enhance the translation of landscape and ecosystem heterogeneity [3] into complex place-based problems. In this way, designed landscape becomes a rug but not a picnic, a scene but not a spectacle, a memory but not a monument, a frame but not a scenery, a patchwork but not a scheme, a construct but not a structure.

In order to permit various research patterns, the topic under the title Learning from the landscape was chosen. Students' research approach should investigate a position of landscape in the process of design, and later through researching complex place-based problems to design an approach that should translate its analogies through imaginative and particular architectural intervention extreme in its relation to the body and context (in the sense of its content, structure, materiality and sensitivity toward nature).

\section{Learning from the landscape - landscape as a mentor}

The question is in which way and by which means landscape as a starting premise affects the process of architectural creation? What are the ways in which architect can direct development of sustainable natural environment as an integral part of urban landscape? What lessons can be learned from observing the landscape and how these lessons as fundamental can lead to the conception of artifacts? How both, nature and architecture can be used to their full potential without being detrimental or destructive to each other?

The focus of this kind of architectural intention is not to incorporate landscape as a part of architectural creation, but to observe and translate landscape is an appropriate tool for thinking about architecture. The main principle behind this kind of approach is that architecture can be guided by people's experience of landscape. We can be guided by observing places that are dominantly formed and evidently caused and variable in relation to natural forces, such as sun, wind, rain and seasonal cycles; but also by vegetation and shapes that are the consequences of geological changes that were created by the changes during the long period. We can learn from landscape lessons about interconnectedness, growth, decay and stability, about continuous adaptability to climate change and of course about the subtle strength.

In various theoretical resources students were looking for answers and in discussions agreed on the importance of few which were incorporated in 
particular place-based problems and later design processes. This led our Studio to the final goal: architecture as multi-sensory experience of landscape.

\subsection{Defining landscape or towards designed nature}

The term landscape is defined in the book The Room in Context, Benzel [4], especially in chapter two: The Room and the Landscape. In essence, landscape is seen as a product of a particular culture's longings and desires, part of a civilization's relationship with the natural world. Author explains that noun "landscape" refers to an expanse of natural scenery taken in by the eye in a single view. The verb "to landscape" implies human intervention, to recreate the landscape in various ways, to change or remodel it as to make it more attractive for use or viewing. Connotations of landscape that were important as a departure points for students were that landscape realizes a person's, society's, or culture's attitude toward space and nature, then that landscape forms have significance and content, encoded meanings which we are able to decode and interpret, and that landscape should be tangible topographically but not spiritually.

In the text Nature and architecture, Van der Laan [5] helped students understand landscape by explaining that it is not just about a contact between our feet and the earth, but about a meeting of our being with the whole natural environment. The harmony is not achieved through a piece of soft ground which "is being under our feet, but through a piece of living space" which is highlighted from the natural environment by the walls.

Encouraged by the text Vacancy and the Landscape: Cultural Context and Design Response, Corbin [6] forest regeneration is seen as the recycling of brownfields, abandoned and forgotten, alienated spaces with fragments of the strong and significant past. Using common phrases like "There's nothing there" she describes landscape that lacks scenic appeal or distinguishable features. Starting from this approach, examining cultural ideas of vacancy and landscape, in terms of how sites are described, perceived and valued, our discussions open up various theories of vacant places and compares strategies of awareness, revealing, openness and occupation.

\subsection{Between landscape and architecture or towards sustainable architecture}

By wondering what sustainability means in the architectural arena,Soria Lopez [7] in Architecture and nature at the end of the $20^{\text {th }}$ century: towards a dialogical approach for sustainable design in architecture argues that really sustainable and simply good must satisfy simultaneously all architectural dimensions: logical (scientific, technical, functional), ethical (security, low impact, protection, good use) and aesthetic (beauty, meaning, emotion) dimensions. In that way sustainability becomes a way, a means to achieve a better life quality for society as a whole, not a goal in itself, just for architecture or nature. This study also helped us in understanding the place through dialogue between man and nature, where natural settings can be registered through the interpretation and valuation of the experience and perception that the inhabitants have through the use of an architectural space. The role of the architect is to incorporate this dialogue into 
the project by listening-understanding-responding to the "voices of the natural and cultural context" and interlock it with the experience of the users of the real place.

As Sustainable was too technological in its definition, we used Smart and Vital architecture as Van Hal [8] in his article The keyword is quality not ecology notes that most architects do not want their work to be associated with green terminology such as 'sustainable or eco-architecture', rather accepting terms like 'smart architecture' [9] or 'vital architecture' [10]. As Van Hal [8] suggests 'Be smart' should be the message instead of 'be green'. Being smart means thinking ahead, building an environment that adapts cleverly and works interdisciplinary, stressing out the quality of it, not ecology in itself. She explains that Vital architecture is a strategy intended to inject new élan into thinking about sustainable building, through various concepts from which the most important for us was that the care for the environment is regarded as an inherent architectural quality, where architecture must not only be environmentally sound, but resilient, dynamic and flexible in its relation between form, function and construction, at all scales and through time.

Moreover she argues that a vital design is more than the sum of its parts; it challenges the architect to selectively integrate and compose all the elements while respecting the constraints of a sustainable context [8].

In short, architects should incorporate the natural in a fundamental manner into their project in order to affect mind and body as a way to improve and intensify our relationship with nature, through architecture - an experience that might increase society's awareness of the urgency to preserve and respect nature.

\subsection{New architectural conditions or towards architecture in accordance with climate change}

Climate is the most notable item in a landscape, so it was inevitable for us to incorporate it into our research dialogue. In respect to the overall urgency of climate change and its connections to the practice of architecture [11] that pressures next generation of architects, students faced the challenge of recognizing architectural tools and methods in accordance with it.

In searching for reflection to our statement that creating climate friendly architecture is all about choice of where, how and what it's made off are crucial as ground, water and air are the main constituents of landscape, students best responded to the article Developing design in balance with nature, in which Anselm [14] explains that the first step towards achieving nature's integral design lies in understanding the natural environment (topography, terrain, management of climate and energy) entailing Ecosystem with its actions and reactions that relates to building design. Later he argues that designing with nature begins with an intimate understanding of place, like designing with existing topography pattern (landform should be carried along in the design concept), carful management of local climate condition and winds, orientation, sun reflections, all with the aim to integrate architecture and natural surrounding at its best.

Following the typological determinates of materiality, through the text $\mathrm{Da} l i$ je arhitekture neophodno materijalna? (Is the materialization of architecture 
necessarily material?) (Carapic [12]) we wanted to explore the potential and limit of the second category: Weak Material - water, air, light, sound, examining their position in the conceptualizing stage of creating architectural form and space in accordance with climate. Absence of the need to accumulate matter increases the sense of enjoyment, elevating the character of the architecture from the primary material to the level of immaterial sensitive dimension. All aspects of metaphor of lightness are reflected in the ability of these weak substances to "take" on themselves the architectural form, emphasizing variety and diversity of states in which artifact defines itself in accordance with climate change.

Stimulated by the book The Eyes of the Skin by Pallasma [13], architectural intervention is seen as an interpretative potential of the sensual experience that accompanies the artificial through every form of human senses, at the very least the sight as predominant in the architectural practice and education. While our experience of the world is formulated by a combination of five senses, a lot of architecture is produced under consideration of only one - the sight. The suppression of the other sensory realms has led to an impoverishment of our environment, causing a feeling of detachment and alienation.

Instead of creating mere objects of visual seduction, architecture relates, mediates and projects meanings. The ultimate significance of any building is beyond architecture; it directs our consciousness back to the world and towards our own sense of self and being.

\section{Towards new paradigms in architectural creation}

A quest for "alternatives" is not in its singular originality, but rather in searching for new methods for sensing relation between natural and artificial, where artifact becomes a bonding element operating directly within the full complexity of our environment.

In summarizing results of the research together with the students we have come to several general conclusions which were pertaining to the possible ways of establishing the connection between nature and architecture.

First of all, the roles of the elements of design are being changed in relation to elements of nature, where architecture becomes a tool for enforcing nature. Second, the power of learning from nature changes material and sensual possibilities of architecture, broadening the ways in which architectural intervention is conceptualized. And finally, recovering landscape is seen through the scope of culture, shaping the cultural landscape through optimizing both architecture's intervention and our spatial imagination.

If we rethink the static nature of architecture and re-imagine innumerable conditions between material and sensual, broadening conceptions of architectural intervention would restructure relations to the body, reframe relations to the context and might argument its diverse logics.

If we redefine culture fusing historic references and contemporary technologies, cultural landscape is shaped through the lens of surreal materiality, where sound, smell, light and shade, touch and psychological interior of nature become leading elements of architectural intervention. 
If we question a pure functional definition of the program and reframe typologies, re-envisioning expectations we have from the landscape, emotional experience of landscape could become a generator for creating a cultured form.

Through the review of students work we will try to show the potential of the theme. Featured works in different ways represent a conscious shift towards designing process that speaks directly about the character and values of particular place.

\subsection{Cultured landscape}

Cultured landscape refers to interventions on the verge of being architecture, shaped through the transformation of the natural landscape itself. Elements of nature are translated into architectural language challenging their potential through its urban articulation and content positioning. It is all nature and nothing but nature exploring extreme values of architectural sensation by blurring the border line between them. Cultural landscape is optimized through its urban content and spatial logic borrowed from the logic of man-made history.

Each of the natural elements earth (rock), sky, water, tree or plant is transformed through intensifying movement, light or topography. Architectural intervention positions itself in natural surroundings, a piece of ground where earth, sky and plant is seen as a purpose, a goal. Recovering landscape is seen through its program, being in the nature, on the ground, under the sky and between plants, contextually connected to natural landscape.

Emphasizing nature with the minimal use of architectural elements proposed designs successfully creates leisure spaces or intimate gardens - "pieces" of nature included in the contemporary urban life as its resting place - the pause.

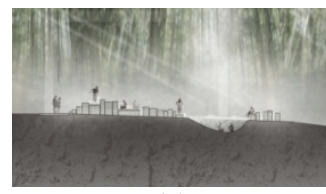

(a)

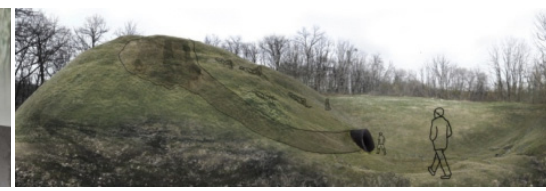

(b)

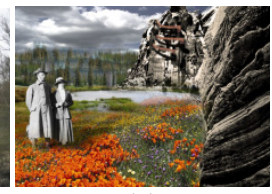

(c)

Figure 2: (a) Milena Vukicevic: House of Earth; (b) Katarina Ristic: Watching Stars; (c) Milos Milovanovic: Temple of Nature.

Stressing the importance of being in balance with nature, these interventions show that it is possible to use nature as structural element of creation, emphasizing a 'smart' way. The focus was on reconciling comfort and ambient, reminiscence, as well as on ethical components of nature. With just a few newly built elements, in accordance with eco-system and climate change, principles of vitality in reshaping nature are achieved.

\subsection{Landscape as a playground}

Landscape as a playground covers a large quantity of small interventions where elements of design intensify natural phenomena challenging the relation between 
body and nature; architecture becomes a tool for enforcing nature through which body explores its sensual limits.

Through determining typical or particular Kosutnjak topography, using Metaphor tools, activity patterns of artificial structure were conceptualized. Being inside, being on the verge and wondering through it highlighted particular human senses through basic architectural elements and their interlocking with natural environment. In this way, design project opens new paths through the forest in a way that we might avoid, by levitating above, inserting between and indenting through. Recovering landscape is seen through the action-reaction relation between man and architectural elements of column, bridge, stairs, lather, platform, by which the forest itself is emphasized.

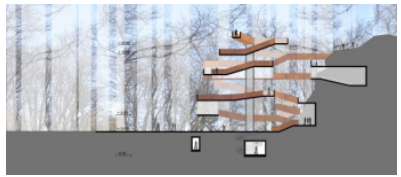

(a)

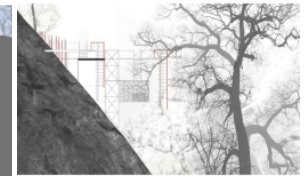

(b)

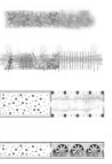

see

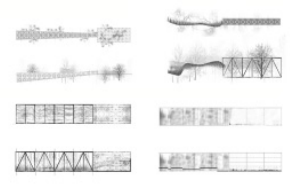

(c)

Figure 3: (a) Tamara Kuljanin: Urban Forest; (b) Tatjana Vorinski: Wondering through; (c) Renata Radovanovic: Meat Industry

Pushing body and nature to its limits, this design projects or more likely constructs emphasize the importance of everything that is found in nature, and what is even more important, it emphasizes the need to preserve it as such, in spite of all anthropogenic, but also natural factors, such as climate change. The focus was on experiential components of nature, on interrelatedness, contradictions and limitations between nature and artificial structure. In this case architecture serves as a means for 'rescuing' the properties of nature and our sense of it. Being "Vital" lies in numerous possibilities of our body and soul to experience nature over and over again.

\subsection{Landscape as a metaphor}

In interlocking nature and architecture through its concept, content, structure, meaning and identity artifacts compete for dominance in humoring both man and nature (in forceful or voluntary way).

These projects have something in common; a need to take a break from the city, where Kosutnjak, being a part of the contemporary urban landscape, is exactly such place. Designs are based on structuring a mechanism for recovery (rehabilitation, dance, theatre, sensing space or alike). Various states are formed in response to the urban city states, through their denial, supporting or enhancing. On the basis of their analysis, spatial units were formed and defined as diagrams of forced rehabilitation. Units are set up as independent or interlocked, but always as a system parallel to or intertwining with natural ecosystem. The project by its position and nature maximizes the potential of modern urban landscapes as well as complementary parts of modern urban city. 


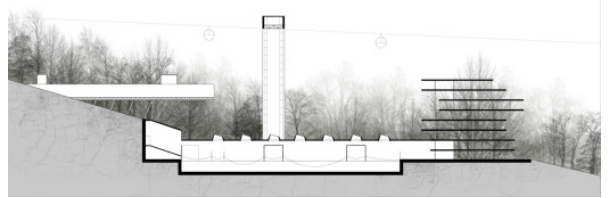

(a)

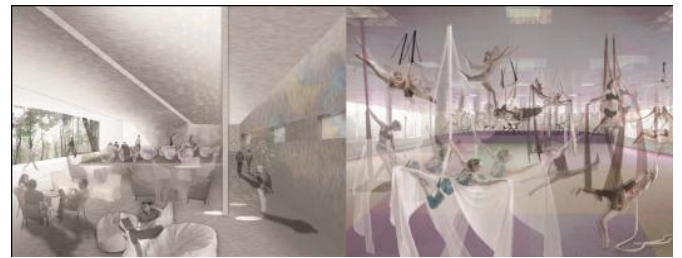

(c) (d)

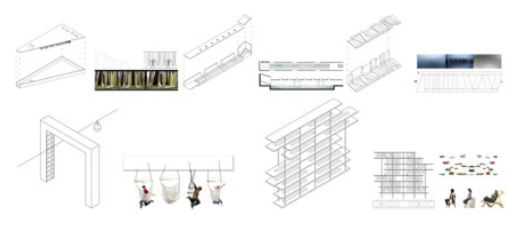

(b)

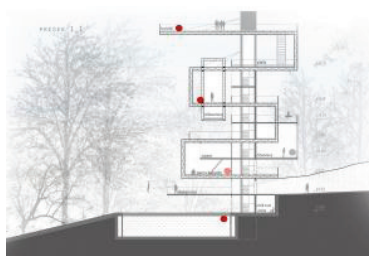

(e)

Figure 4: (a) and (b) Marko Slavkovic: Forced Rehabilitation; (c) and (d) Renata Djuric: Purgatory; (e) Jelena Arandjelovic: Sin City.

In this case it may be argued that architecture serves as a framework for the artificial processes familiarized with nature, like a box that keeps the naturalness alive, as a reminder of the importance of incorporating nature into urban landscape as part of contemporary life. The focus was on increasing subjectivity in understanding natural forces and to be aware of the limits of the world that surrounds us. It can serve as a message that our generation needs to regenerate nature in order to be resilient to the process of climate change but at the same time to reflect contemporary urban lifestyle.

\subsection{Landscape as a mentor}

Architecture becomes a cultural generator challenging natural landscape as its opponent. Architecture challenges itself forcing context to become an urban life incubator. They create another nature, over and over again, emphasizing a way of perceiving it depending on a way we are familiar with it. Projects quickly and successfully demonstrate what it is in the natural environment that often goes unnoticed.

By pointing out ways in which someone can look at, track, investigate or explore nature (its particular parts, elements and characteristics), depending on the way we choose to take, diverse possibilities to "feel" the nature in a certain way are open up before us. Each passage, whose character can be partly enhanced, leads through the fragments of nature down to the real nature.

In this way architecture serves as the infrastructure for the nature, facilitating it in various ways. Sometimes fragments of nature are locked, enclosed or duplicated, but architecture does not take away from nature, but rather, paradoxically, supplements nature and increases it, making it a resource for what we can easily run out due to negligence and urban development. The main focus 


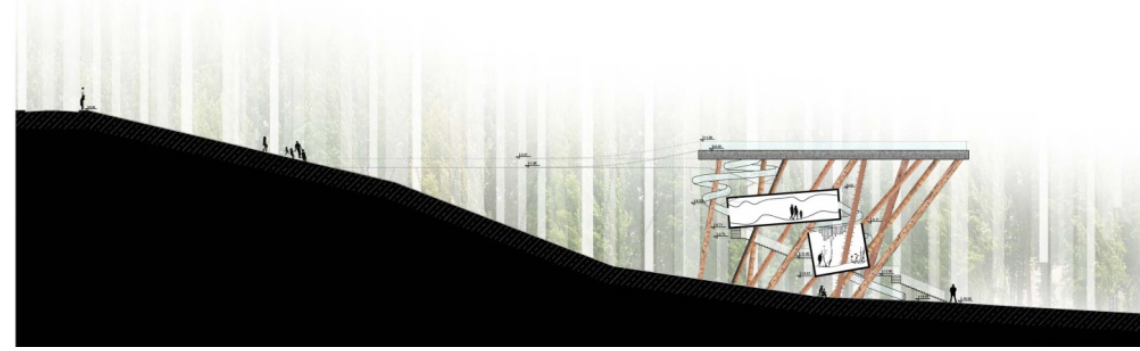

Figure 5: Nemanja Kocic: Rollercoaster.

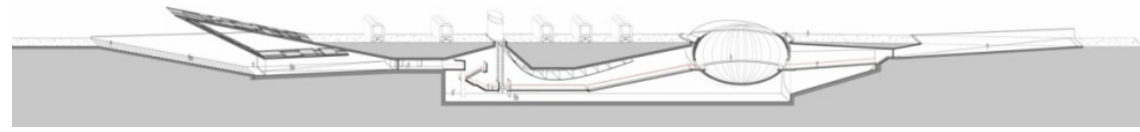

Figure 6: Marija Obradovic: A fresh look onto Kosutnjak.

of this group of designs was on seeing the magnificent diversity of the particular place of Kosutnjak, as a system inside a city worth preserving and managing in smart and vital way.

\section{In conclusion}

Changeable effects of sound, texture, color, form, light, and shadow stimulate our mind, arouse our senses, and evoke an appreciation of beauty and harmony, as well as a whole range of emotions for reflection. The landscape, so richly textured, intensely scented and vividly endowed with color and light, gives us a sensation of active participation even when we are merely sitting and reflecting [4].

As the author of The Eyes of the Skin emphases, a distinct sense of distance, resistance and tension can be maintained in relation to program, function and comfort. A piece of architecture should not become transparent in its rational motives, but rather maintains its impenetrable secret and mystery in order to ignite our imagination and emotions.

The results show that the design in the natural environment, with the right approach, guided by the synergy between nature and architecture brings a new and better architecture, which also emphasizes the quality of that from which it drew inspiration from and was created for - a living landscape.

Opposite to the observation of nature as something that is outside the field of architecture, this course was intended to set the landscape as an integral part of architectural mechanisms. Equalization of these two fields of activity, natural and artificial, where both forces of activity are equally strong, a result ranged from nature as architecture, through accentuating one or another to architectural structure capable of forcing nature to change. 
In this way architectural "control" of natural substances creates new, technological nature, in conjunction with a different, naturalized architecture. Natural and artificial mechanisms, however, are not in antagonism. They shared "work" in the disappearance and the emergence of different forms of materiality. Where the first disappears, there is the other matter, a new, artificial nature.

\section{Acknowledgement}

This paper was realized as a part of the project "Studying climate change and its influence on the environment: impacts, adaptation and mitigation" (43007) financed by the Ministry of Education and Science of the Republic of Serbia within the framework of integrated and interdisciplinary research for the period 2011-2014.

\section{References}

[1] Longstreth, R., (ed.). Cultural Landscapes. Balancing nature and heritage in preservation practice. University of Minesota Press: Minneapolis and London, 2008.

[2] Naveh, Z., Ten major premises for a holistic conception of multifunctional landscapes. Landscape and Urban Planning, 57, pp. 269284, 2001.

[3] Masacchio, L.R., The scientific basis for the design of landscape sustainability: A conceptual framework for translational landscape research and practice of designed landscapes and the six Es of landscape sustainability. Landscape Ecol, 24, pp. 993-1013, 2009.

[4] Benzel, F.K., The room in context. Design beyond boundaries: Princeton architectural press: New York, 1996.

[5] Van der Laan, D.H., Nature and Architecture. Architectonic Space: Fifteen Lessons on the Disposition of the Human Habitat: Brill academic Publishers: Leiden, pp. 1-11, 1983.

[6] Corbin I.C., Vacancy and the Landscape: Cultural Context and Design Response. Landscape Journal, 22(1), pp. 12-24, 2003.

[7] Soria Lopez, F.J., Architecture and nature at the end of the $20^{\text {th }}$ century: towards a dialogical approach for sustainable design in architecture. WIT Transactions on The Built Environment, 86, pp. 23-33, 2006.

[8] Van Hal, A., The keyword is quality not ecology. Eco-Architecture: Harmonisation between Architecture and Nature. WIT Transactions on The Built Environment, 86, pp. 35-44, 2006.

[9] Foundation for smart architecture, www.smartarchitecture.org

[10] Association of Dutch Architects, www.bna.nl

[11] Van Ypersele, J.P., Climate change, cities, and the IPCC, Sustainable City/Developing World. ISOCARP Review, 06, pp. 80-88, 2010.

[12] Carapic, A., Da li je materijalizacija arhitekture neophodno materijalna? (Is the materialization of the architecture necessarily material?). Arhitektura I Urbanizam, 22-23, pp. 25-33, 2008. 
72 Design and Nature VI

[13] Pallasma, J., The Eyes of the Skin: Architecture and the Senses, $2^{\text {nd }}$ edition, Wiley: New York, 1996.

[14] Anselm, A.J., Developing designs in balance with nature. EcoArchitecture: Harmonisation between Architecture and Nature. WIT Transactions on The Built Environment, 86, pp. 195-205, 2006. 